\title{
Recortes de uma vida de intervenção inspirada em Paulo Freire
}

\author{
Alberto Melo \\ "Ser cultural ou ser consciente é a forma radical de \\ ser dos humanos, enquanto seres que, refazendo o \\ mundo que não fizeram, fazem o seu mundo e, neste \\ fazer e refazer, se refazem a si mesmo. São, porque \\ estão sendo."
}

Como esta, são inúmeras as frases de Paulo Freire ${ }^{1}$, vincando o direito e o dever de cada pessoa se afirmar como sujeito da sua história e, como tal, da história do mundo. Numa linha de pensamento, talvez iniciada por Baruch de Espinoza - quando pretendeu explicar as relações dinâmicas entre a construção de cada pessoa e a sua sociedade política - Paulo Freire oferece-nos simultaneamente uma visão (tornarmo-nos efectivamente pessoas) e um programa: agir sobre nós mesmo, agindo sobre o mundo, para nos aproximarmos incessantemente dessa visão, sabendo embora que o processo ficará por natureza inacabado.

Entre meados das décadas de 60 e de 70, na situação de exilado político, trabalhei no âmbito de um organismo internacional, em Paris, e seguidamente, numa Universidade inglesa. Foi aqui que, pela primeira vez, ouvi falar de Paulo Freire e li algumas referências indirectas à sua pessoa, aos seus escritos e às suas actividades. Quando regressei, após Abril de 1974, e tive 
oportunidade de coordenar, durante uns 9 meses, o departamento da Educação de Adultos do Ministério da Educação (DGEP), foi então possível lançar um conjunto de iniciativas, ditas de "educação popular", que procuravam reformar radicalmente os conteúdos e, sobretudo, os processos de educação para as pessoas adultas, numa estratégia de parceria activa entre o Estado e a sociedade civil organizada. Peritos portugueses, e até suecos, que nos ajudavam a definir e aplicar os novos instrumentos, referiam amiúde a ligação estreita entre tais medidas e o pensamento de Paulo Freire. Pessoalmente, devo confessar que, eu e as pessoas que me acompanhavam neste empreendimento, procurávamos apenas começar a construir uma nova educação de adultos para um país em vias de democratização, uma educação feita com os próprios cidadãos e visando a sua gradual autonomia, feita de pensamento crítico e de intervenção activa e consciente. Só uns anos mais tarde, pela mão de um grande amigo (Ettore Gelpi, então responsável pela Unidade de Educação Permanente, na UNESCO), tive o feliz ensejo de conhecer e de trocar umas palavras com Paulo Freire, primeiro em Paris, num colóquio da UNESCO e, mais tarde, em Genebra, na casa de uma filha sua.

Em contraste com sistemas filosóficos e ideológicos que reduzem o indivíduo a uma mera resultante, passiva ou impotente, de condicionalismos determinantes, emerge da filosofia de Paulo Freire uma fundamental margem de liberdade, que é simultaneamente margem de responsabilização, para cada um de nós, como seres humanos. Porém, esta liberdade só será libertação à medida que - pela acção, e pela reflexão que façamos dessa acção - cada pessoa se for tornando mais consciente, mais autónoma, mais eficaz e eficiente na acção que exerce sobre si, sobre e com os outros, sobre e com o mundo. Em suma, libertar-se-á à medida que, ao influenciar e deixar-se influenciar, se for tornando mais pessoa. Não será, contudo, de uma forma automática que todos assumirão a tarefa, sempre penosa, da responsabilização pessoal, isto é, da conquista dos direitos-deveres de participar activamente na construção da própria vida e das respectivas comunidades e sociedades. É, portanto, necessário iniciar / reforçar processos de intervenção, visando sensibilizar as pessoas para "horizontes por descobrir" e capacitá-las para uma participação informada e confiante nessa descoberta e na abertura e transformação dos actuais (curtos) horizontes. É aqui que se torna imprescindível a educação, mas uma só forma de educação - a que vise a libertação, e não uma pretensa "educação" - o treinamento - direccionada apenas para o conformismo e o ajustamento ao "status quo" existente e dominante.

Assim, é evidente que o espaço público - o espaço aberto à intervenção humana sobre a sua sociedade - ultrapassa em muito o espaço reservado ao trabalho dos políticos de profissão. A sociedade não se transforma apenas através das leis, das grandes reformas, das mega-estratégias, mas estará a evoluir sempre que cada um de nós pensa e age em coerência, visando o aperfeiçoamento próprio e o dos outros, e sempre que um grupo de cidadãos empreende um processo - por mais pequeno que 
seja - de aprendizagem colectiva através de uma acção reflectida. Estamos em plena acção educativa, logo que, como nos diria Paulo Freire, pudermos "melhorar a condição humana, contrariando os efeitos da psicologia da opressão".

Vêm estas considerações a propósito de uma experiência de intervenção de natureza socioeducativa, iniciada em 1985, a partir de um pequeno grupo de pessoas, sediadas na Escola Superior de Educação de Faro. (De início, o Projecto RADIAL e, desde 1988, a Associação "In Loco"). Qual a causa próxima dessa iniciativa? Por um lado, a constatação de uma enorme assimetria entre as condições de vida no litoral do Algarve e no seu interior serrano, como resultado da expansão à escala planetária de um modelo dominante de acumulação de capital e de concentração de investimentos, subordinado exclusivamente ao princípio da maximização do lucro, da rendibilidade. Por outro lado, a convicção de que a resistência a um modelo destruidor de valores que são, para nós e para muitos outros, essenciais, não poderia resumir-se a inserir, por via tecnocrática, esse território no processo de expansão capitalista em curso. Por fim, a consciência de que um espaço de intervenção cívica assim criado se tornaria, a breve trecho, numa "escola de cidadãos" capazes de analisar rigorosamente a sua situação pessoal e a sua sociedade e de encontrar as vias mais coerentes e apropriadas para intervir, de forma integrada, participada e geradora de autonomia, em qualquer tipo de contexto social e geográfico.

Para delinear e concretizar, gradualmente, este processo de actuação, é óbvio que nos acompanhou em permanência o pensamento de Paulo Freire. Muito mais, aliás, a sua filosofia do que o seu reputado modelo pedagógico. Acima de tudo, a sua crença na natureza perfectível de todas as pessoas, uma vez envolvidas em dinâmicas conducentes à libertação, ou a sua demonstração de como "um processo de conquista da autonomia pessoal é detonador do processo para uma sociedade mais livre". Não partimos de um plano prévio de acção, exaustivo e estanque, mas sim dos resultados de contactos interpessoais nas aldeias, de reuniões gerais com as populações. Vivíamos na incerteza, que é - nas palavras de Paulo Freire - "o único lugar de onde é possível trabalhar de novo necessárias certezas provisórias”.

Partimos para a invenção comum de respostas adequadas, definidas no diálogo, ou até no confronto, de ideias, entre a equipa de intervenção e os residentes. Como Paulo Freire também nos diz, "o intelectual precisa saber que sua capacidade crítica não é superior nem inferior à sensibilidade popular; a leitura do real requer as duas". Organizámos instrumentos e momentos para a reflexão sobre a prática em curso. Tal como o "radical" em Paulo Freire (e radical é ir até à raiz das coisas), "rejeitámos o activismo e submetemos sempre a acção à reflexão, reconhecemos que, se não podíamos deter nem antecipar, podíamos e devíamos, como sujeitos, com outros sujeitos, ajudar e acelerar as transformações desejáveis, na medida em que íamos conhecendo melhor para melhor poder interferir". 
Definimo-nos à partida como um projecto de acção-investigação-formação e mantivemos esse compromisso de prosseguir um processo que foi fundamentalmente educativo e que, por isso mesmo, tinha de assentar nesses três pilares. Conceber e executar um projecto de intervenção desta natureza numa zona em crise cultural e económica, como é o interior do nosso país, exige uma ruptura drástica com os padrões convencionais de ensino baseados em espaços especializados para a transmissão de conhecimentos, numa relação unidireccional professor-aluno e em conteúdos programáticos pré-definidos.

A acção educativa não pretende ser, e não pode ser nestes casos para se tornar eficaz, uma simples extensão institucional, alargando a sua clientela para produtos inalterados. Se a acção educativa quer contribuir de facto para a gama de respostas exigidas por situações-problema, não é possível iniciar de imediato actividades formais de educação ou formação. Lançar cursos, sem um prévio trabalho de reconhecimento e escuta das aspirações, capacidades, recursos e necessidades locais, não seria mais que reproduzir os interesses, motivações e saberes dos próprios docentes - sem qualquer garantia de os adequar realmente às situações sobre as quais se pretendia intervir. É aqui essencial a humildade de assumir a posição de "fornecedor" de algumas respostas parciais, face a solicitações que só são expressas de forma efectiva e rigorosa nos próprios locais e momentos de uma intervenção capacitadora.

Neste processo, foi fundamental à equipa de intervenção saber ouvir e saber aprender, antes de saber falar ou saber ensinar, a fim de criar uma dinâmica partilhada na busca de respostas compreensíveis e adequadas. Nas palavras de Paulo Freire: "Ninguém ensina o que não sabe. Mas também ninguém deveria ensinar o que sabe, sem, de um lado, saber o que já sabem, e em que nível sabem, aqueles e aquelas a quem vai ensinar o que sabe"; ou ainda: "Devemos procurar a construção do conhecimento colectivo, articulando o saber popular e o saber crítico, científico, mediado pelas experiências no mundo."

Cursos profissionais e projectos de investigação aplicada puderam ser utilizados, sim, mas uma vez integrados na dinâmica em curso, como fecundos espaços de interacção entre actores, entre culturas, entre saberes. Tal foi o caso, entre muitos, da tecelagem manual, assente nos contributos técnicos, tanto de uma tecedeira local como de "designers" vindos do exterior, e onde as mulheres participantes receberam elementos de teoria da cor ou de debuxo, que lhes permitiram passar de uma condição de meras executoras, reprodutoras de antigos padrões, à de reais criadoras. Ou os cursos de doces tradicionais ou de plantas aromáticas, sempre precedidos de uma recolha exaustiva dos saberes e saber-fazer tradicionais, mas sempre igualmente enriquecidos com contributos exteriores, numa busca constante de sínteses criativas entre a tradição e a inovação. 
Também projectos de investigação colocados ao serviço do desenvolvimento do território serrano, como os referentes à aguardente de medronho, à utilização da energia solar ou à raça caprina algarvia, souberam combinar conhecimentos locais e científicos, souberam alternar a investigação on farm e on station, de modo a produzir resultados rigorosos e enquadrados com as reais necessidades dos produtores locais e as tendências dos mercados externos.

O que se torna necessário, acima de tudo, é criar situações educativas, contextos dinâmicos em que se insiram grupos significativos de pessoas (em número e em qualidade), em redor de problemáticas que afectam efectivamente a vida quotidiana; problemáticas essas que geram sempre oportunidades de desenvolvimento, nas áreas do cognitivo, do estético-afectivo, do fisico-motor, das técnicas, da sociabilidade, etc. Ora, para que se criem estas situações, estas dinâmicas educativas, o ponto de partida (uma vez efectuado, em comum, um breve diagnóstico prévio) quase se poderia dizer que é indiferente, na condição de agregar o interesse de um grupo local, por pequeno que seja de início.

Do local se passa naturalmente ao global. Como tão bem nos diz Paulo Freire: "Quanto mais enraizado na minha localidade, tanto mais possibilidade tenho de me mundializar. Ninguém se torna local a partir do universal. O caminho existencial é o inverso." Também o nosso Miguel Torga nos ensinou que "o universal é o local sem paredes." E, como há anos nos relembrou Michael Apple, "nestes tempos neoliberais, precisamos de voltar a Paulo Freire para nos lembrarmos das preocupações éticas e políticas que devem animar o nosso criticismo social e ideológico, para nos lembrarmos da importância de nos empenharmos na verdadeira educação crítica, para refazer a conexão com os sonhos, visões e até mesmo com esperanças utópicas que são negadas numa sociedade em que os lucros contam mais do que as pessoas."

Em finais de 1997, troquei temporariamente o local pelo global, ao ser convidado (por Ana Benavente) a coordenar um processo de renovação do sistema de educação e formação de adultos em Portugal. E foi então possível perspectivar, por um lado, a criação de uma estrutura institucional exclusivamente dedicada a este sector e, por outro, a construção gradual de um sistema coerente e independente do modelo escolar, que se ajustasse, de facto, às características próprias das pessoas adultas. Entre as várias medidas então implementadas, sublinho uma que, a meu ver, se encontra em grande sintonia com os ensinamentos do nosso mestre Paulo Freire. Dizia-nos ele: "Subestimar a sabedoria que resulta necessariamente da experiência sociocultural é, ao mesmo tempo, um erro científico e a expressão inequívoca da presença de uma ideologia elitista... Não é possível aos educadores desconhecer, subestimar ou negar os saberes de experiência feitos com que os educandos chegam à escola." 
Para a minha tomada de consciência da necessidade de delinear qualquer processo educativo com a população adulta numa prévia compreensão do que cada pessoa já adquiriu, ao longo da vida, como conhecimentos e competências, foi essencial a experiência que eu próprio ganhara durante os anos de trabalho na Serra Algarvia, entre 1985 e 1997. De facto, os contactos pessoais entre a equipa de intervenção que então coordenei e os residentes das aldeias e montes da serra algarvia geraram um processo de aprendizagens recíprocas e também colectivas, que persistiram até final do Projecto. Trata-se de um território de muito pequena propriedade, de forte tradição de independência pessoal (embora assente na unidade familiar), centrada na pluriactividade e reforçada na luta ancestral pela sobrevivência em situação de forte isolamento. Era, pois, frequente o encontro com pessoas, normalmente as que tinham mais de 60 anos, que sabiam e faziam tudo o que era necessário ao seu quotidiano: construir e reparar a casa, gerir a água, instalar e fazer funcionar sistemas de regadio ou de sequeiro, tratar da horta, criar animais e transformá-los em alimentação, preparar lã ou linho para tecer o vestuário e outros artigos, etc., etc. Tanto saber, tantas competências indispensáveis ao dia-a-dia, por parte de pessoas que, no seu diálogo com os profissionais do projecto, se declaravam "totalmente ignorantes", pois desconheciam as letras, nunca tinham ido à escola, não possuíam qualquer diploma...

Era óbvio que, no início do século XXI a população adulta portuguesa não era, como hoje não é, tão «ignorante» quanto o mero reflexo da sua fraca escolaridade poderia sugerir. A integração em geral bem sucedida dos emigrantes portugueses na Europa e no mundo, a transição pacífica de uma sociedade ditatorial para um regime democrático, a inserção de mais de meio milhão de pessoas vindas das antigas colónias, a construção em poucos anos de uma sociedade mais moderna que nos conduziu ao Clube do Euro, não podem ser obra de uma população sem qualificações. Mais do que subqualificada, a população adulta portuguesa era, e continua de certo modo a ser hoje, sub-certificada, o que atesta sobretudo o carácter monolítico e inflexível dos nossos sistemas de certificação. Sistemas que têm ignorado a intensidade e a qualidade do esforço de autoformação, realizada pelos adultos em contextos de vida e de trabalho.

Por isso se defendeu então, como hoje continuo a defender, como um dos pilares do sistema de educação e formação de adultos em Portugal, que os saberes e as competências adquiridos fora das vias formais de ensino ou de formação profissional sejam sempre considerados; através de uma análise rigorosa, com a participação activa dos interessados, e culminando num reconhecimento formal, que se traduza numa validação oficial. Conduzindo sempre a uma creditação, isto é, outorga de créditos convertíveis em equivalências: ou equivalência parcial, correspondendo a dispensa de uma certa parte do percurso formal de educação e formação; ou equivalência total, correspondendo a uma certificação automática e à outorga imediata de um diploma oficial. 
Apesar das muitas barreiras que se levantaram, dos desvios sofridos e dos longos períodos de hostilidade ou de indiferença ao nível da decisão política, esta filosofia e as medidas dela decorrentes conseguiram manter-se ao longo dos últimos 20 anos. E sinto que podemos encontrar-nos agora, em Portugal, num novo patamar de desenvolvimento da educação e formação de adultos, assente na vitalidade renovada da sociedade civil e na vontade política de superar o problema centenário das baixas qualificações da população adulta.

Permitam-me, por fim, despedir-me com estas belas palavras de Paulo Freire, que muito gostaria (e certamente muitos de vós também) de poder um dia fazer minhas: "Sou leal ao sonho. Minha acção tem sido coerente com ele. Exigente com a ética, considero que ela tem a ver com a coerência com que se vive no mundo, coerência entre o que se diz e o que se faz... Continuem contando comigo na construção de uma política educacional, de uma escola com outra cara, mais alegre, mais fraterna e democrática."

Nota

1 Comunicação no Seminário "Paulo Freire e a Pedagogia do Oprimido: 50 anos de presença nas sociedades", 30 de Novembro de 2018, Universidade Lusófona, Lisboa.

Alberto Melo

Presidente do Conselho Executivo da Associação Portuguesa para a Cultura e Educação Permanente, APCEP 